\title{
VEINTICINCO AÑOS DE SENADO
}

ANTONIO TORRES DEL MORAL

Catedrático de Derecho Constitucional UNED 


\section{SUMARIO}

1. LA OPCIÓN CONSTITUYENTE BICAMERAL. 2. DeMOCRACIA DE PARTIDOSY SISTEMA ELECTORAL AL SENADO. 3. BicAMERALISMO IMPERFECTO (Y FALLIDO). 4. LA REFORma del Senado como problema. 5. Propuestas de Reforma habidas duRante los años noventa. 6. Creación de la Comisión General de las Comunidades Autónomas. 7. Reforma constitucional del Senado. 7.1. Búsqueda de un modelo de Senado como Cámara autonómica. 7.2. Composición, estatuto de sus miembros e indisolubilidad. 7.3. Función legislativa del Senado. 7.4. Otras funciones. 8. BALANCE. 


\title{
VEINTICINCO AÑOS DE SENADO
}

\author{
POR \\ ANTONIOTORRES DEL MORAL \\ Catedrático de Derecho Constitucional \\ UNED
}

\section{LA OPCIÓN CONSTITUYENTE BICAMERAL}

La construcción del Estado autonómico a partir del acusado centralismo franquista ha sido seguramente la apuesta más arriesgada del constituyente español en un principio, y del legislador estatuyente más tarde. Se trataba de construir un Estado casi de nueva planta, para lo que había que vencer muchas inercias, si bien tenía a su favor el viento de la Historia, que hacía necesaria, casi inevitable, esa tarea.

El Estado autonómico ha venido funcionando hasta hoy razonablemente bien, 0 , por decirlo de un modo más relativista, no del todo mal, aunque se han podido detectar varias "asignaturas pendientes", cuales son, entre otras, la carestía de su funcionamiento, el problema de la financiación, el escaso o nulo incremento de la solidaridad interregional... y el Senado.

La opción bicameral se mantuvo a lo largo de todo el proceso constituyente español, pero varió mucho su configuración como segunda Cámara. El resultado final estuvo determinado por varios factores, a cual más importante:

1. ${ }^{\circ}$ La inercia institucional: difícilmente un bicameralismo constituyente podría depararnos una solución monocameral de futuro. Y el resultado no sólo fue bicameral, sino que el Senado quedó perfilado de modo parecido al constituyente. 
2. ) La demanda de que los órganos centrales, concretamente las Cortes, reflejaran la estructura territorial del Estado. EI constituyente español nunca puso en duda lo que nadie suele poner en duda: que un Estado territorialmente compuesto debe de tener un Parlamento bicameral, para representar en una Cámara a la población de todo el Estado y en otra a los territorios federados o autónomos.

A mi juicio se trata de un hecho constitucional generalizado, no de un principio general del Derecho Constitucional. Una cosa es que, en estos supuestos, haya dado buen resultado el bicameralismo $y$, por tanto, sea prudente instituirlo (vamos a suponerlo así, aunque se pueden señalar muchas excepciones), y otra muy diferente es que sea consustancial al Estado territorialmente compuesto. La sola evocación de nuestra II. ${ }^{a}$ República, que, siendo un Estado regional, estableció unas Cortes monocamerales, puede servirnos de ilustración. Pero lo decisivo, en nuestro caso, fue que el constituyente español, como otros tantos en su caso, creía o parecía creer en ello.

3. ${ }^{\circ}$ También influyó la inclinación de algunos sectores políticos a crear una Cámara conservadora junto al Congreso de los Diputados.

Cada grupo buscaba, pues, un Senado diferente. En un momento inicial se intentó dar respuesta a las demandas autonómicas mediante un Senado de representación de las Comunidades Autónomas, con un cupo de senadores cooptados por éstas. Más adelante se desechó el modelo anterior sin que se lo sustituyera por otro. Al final se construyó uno en el que casi desapareció su carácter territorial y se acentuó su naturaleza conservadora.

La redacción de los preceptos correspondientes varió, pues, mucho durante el proceso constituyente $y$ al final se adoptó, mediante un compromiso que no satisfizo a nadie, pero con el que nadie estaba en frontal desacuerdo, un bicameralismo imperfecto, con un Senado elegido mediante un sistema electoral diferente del empleado para el Congreso y con unas facultades legislativas y de control bastante disminuidas. El resultado quedó, por tanto, muy desfigurado. Según M. Caciagli, la territorialidad del Senado es un mero apéndice retórico. Para R. Punset, el Senado resultante es híbrido, básicamente conservador, sumido, a fuerza de mestizajes, en la indefinición y en la contradicción, pues, siendo democrático en su composición por estar elegido por sufragio universal, tiene disminuidas sus facultades legis- 
lativas y no puede censurar al Gobierno, pero éste sí puede disolverlo; además, es definido como Cámara territorial, pero es el Congreso el que ostenta la primacía incluso en las cuestiones autonómicas, con alguna excepción; $y$, en fin, entre otras asimetrías, el Congreso es el único que convalida los decretos-leyes y el único que interviene en los estados de anormalidad constitucional.

\section{DEMOCRACIA DE PARTIDOSY SISTEMA ELECTORAL AL SENADO}

La democracia de partidos hace el resto. La alineación de los senadores "autonómicos" con los grupos parlamentarios ideológicos le resta al Senado un elemento importante de Cámara territorial, sin que los denominados "grupos territoriales" hayan supuesto solución alguna.

Porque no es casual, en este orden de consideraciones, que el sistema electoral para el Senado haya sido consagrado por la Ley tal como lo estaba preconstitucionalmente: un sistema de mayorías, con cuatro senadores elegidos en cada provincia (no por ellas), salvo las provincias insulares, Ceuta y Melilla, y un contingente (que apenas supera el $19 \%$ ) de senadores cooptados por las Comunidades Autónomas. Este sistema, con predominio total de la circunscripción provincial, más el voto limitado (voto a tres candidatos como máximo, lo que asegura normalmente la representación de una minoría en cada provincia), acerca mucho los resultados electorales de las dos Cámaras, no habiéndose dado todavía unas mayorías disímiles y simultáneas. Antes bien, la mayoría del Senado suele ser más acentuada y del mismo signo que la del Congreso, lo que refuerza su subordinación a éste.

Por lo demás, los senadores "autonómicos», son designados por las Asambleas Legislativas de sus respectivas Comunidades Autónomas en proporción a los efectivos de cada fuerza política en la Cámara. (En esto son más proporcionales que los representantes de los Gobiernos de los Länder en el Bundesrat alemán). No está excluida, sino que es frecuente, la designación como senadores de diputados del Parlamento autonómico; son cargos compatibles. El Estatuto catalán incluso lo exige así. 


\section{BICAMERALISMO IMPERFECTO (Y FALLIDO)}

El Senado no es propiamente una Cámara territorial, ni podía serlo del todo: en la Constitución española no estaba todavía dispuesto por completo el Estado autonómico; aún no se sabía con certeza cuántas Comunidades Autónomas iban a constituirse, ni cuáles, ni con qué alcance descentralizador, ni con qué instituciones internas. Es verdad que ya se percibía una generalización del fenómeno preautonómico y, por eso, el constituyente pudo haber sido algo más previsor. Pero no menos cierto es que la Constitución no procede a regionalizar el Estado, sino a posibilitar que esto se hiciera posteriormente.

La generalidad de la doctrina (Punset, Álvarez Conde, Fernández Segado, Chueca, Portero, yo mismo...) califica negativamente el bicameralismo español y entiende que el Senado no responde a un diseño concreto: tiene algo de Cámara conservadora y algo de Cámara territorial. A. Manzella califica de procedimental, más que de estructural, el bicameralismo español. R. Chueca se muestra más comprensivo, hablando, con razón, de que la Constitución porta varios bicameralismos a un tiempo $Y$ J. A. Portero ve algunas posibilidades de protagonismo del Senado, si, dado un cierto equilibrio de las dos grandes fuerzas políticas españolas, las mayorías de ambas Cámaras no coincidieran, hecho que, sin embargo, no ha sucedido nunca.Y, por no alargar la lista de autores, en definitiva, como dice M. Aragón, siendo parlamentario el sistema de gobierno español, lo más característico de la actuación de las Cortes en relación al mismo es ejercido unicameralmente.

Durante veinticinco años ha sido más una Cámara secundaria que una segunda Cámara, y su percepción por parte de la opinión pública ha sido prácticamente nula. No obstante, en los últimos años ha sido utilizada, de manera imprevisible, como Cámara correctora de los proyectos de ley, con rectificaciones de hondo calado, que después el Congreso puede aceptar o rechazar en bloque, sin nuevo debate, dándose la circunstancia de que esta Cámara aceptaba enmiendas senatoriales importantes, con lo que queda burlado el debate con la Oposición sobre ellas. No parece ser ésta la misión de una Cámara de segunda lectura, pero, por la similar mayoría política en ambas, ha sido utilizada de manera limitadora del debate parlamentario, lo que es tanto como decir del pluralismo político. Esperemos que el ejemplo no cunda, porque, si esta desviada utilización se hace sistemática, es mejor no tener segunda Cámara y que todo el debate político, poco o mucho, se desarrolle en una sola; pues, si dicha práctica no vulnera la letra de nuestra norma suprema, sí vulnera, y mucho, su espíritu. 


\section{LA REFORMA DEL SENADO COMO PROBLEMA}

Así, pues, el Senado no satisfizo a nadie. Fueron muchos los que, ya desde el principio, abogaron por su reforma. Después, a los dieciocho años de vigencia constitucional, parecía haber consenso para ello en la legislatura que se iniciaba (1996-2000). Ahora, a los veinticinco años del feliz alumbramiento constitucional, el partido del Gobierno ha cancelado el asunto. Todo lo cual tiene su explicación, como veremos en su momento.

Dos de los problemas a dilucidar estriban en convenir el tipo de Senado que se quiere y el alcance de la reforma que se está dispuesto a hacer. Uno y otro problema están evidentemente conectados entre sí. La dificultad mayor para una nueva configuración del Senado reside en si exige o no una reforma constitucional. Para que una Cámara merezca el nombre de territorial es preciso que lo sea por su composición y por su funcionamiento, siendo lo primero presupuesto de lo segundo. Es decir: no cabe atribuir al Senado funciones decisivas respecto del Estado autonómico sin modificar su composición para que represente a la población de las distintas Comunidades Autónomas, y es un contrasentido dotarlo de tal representación si sus funciones continúan siendo una reduplicación subordinada de las del Congreso. $Y$ esto no se consigue sino con una reforma constitucional.

Ahora bien, a este respecto, tanto en sede política como en sede académica ha habido hasta 1996 y, luego, desde el año 2000, un rechazo generalizado (o mayoritario, según las fechas) de la idea, de la mera idea, de la reforma del texto constitucional. Tan sólo Alianza Popular enarboló al principio la bandera de la reforma, refiriéndola al Estado autonómico; sin embargo, posteriormente no insistió en ello y la formación política que le ha sucedido, el Partido Popular, ha sido escasamente proclive a la reforma constitucional, posición que ha acentuado en nuestros días.

Y ello es así porque se ha venido entendiendo que resultaria muy dificil reconstruir el clima de consenso que presidió el proceso constituyente y que, por eso mismo, ere imprudente iniciar una reforma que nadie estaba en condiciones de garantizar cómo acabaría. Los constitucionalistas, en sede académica, han coincidido, por lo general, con este planteamiento.

No obstante, el hecho de haberse realizado ya una reforma del texto constitucional, bien que mínima, pero sin ningún trauma y con un nivel de consenso muy alto entre todas las fuerzas políticas pare- 
ció persuadir a los actores políticos de la desdramatización de una eventual reforma constitucional del Senado. Por eso, ya al término de la legislatura 1889-1893, y, desde luego, durante la campaña electoral de mayo-junio de 1993, casi ningún partido descartaba que la reforma del Senado se hiciera mediante una modificación de la norma suprema. Parecía que se estaba esfumando el miedo a la reforma constitucional. No obstante lo cual, el procedimiento preferido era el de la reforma del Reglamento del Senado, mucho menos costoso políticamente.

\section{PROPUESTAS DE REFORMA HABIDAS DURANTE LOS AÑOS NOVENTA}

Nada sorprenderá entonces que las propuestas hechas, cuando se hicieron, por parte de las fuerzas políticas no pasaran apenas de la reforma del Reglamento de la Cámara y, en su caso, de la Ley Electoral. Así las cosas, los grupos parlamentarios del Senado llegaron a un acuerdo mínimo: el de la necesidad de modificar por consenso el primer texto aludido. Cada uno hizo su propuesta bajo la idea directriz (aunque no única), compartida por todos, del necesario incremento del carácter de Cámara territorial que hasta entonces apenas había tenido el Senado (y sigue sin tenerlo). Veámoslas sucintamente:

I. El Grupo Parlamentario Socialista se fijaba preferentemente en las siguientes cuestiones:

a) Designación de senadores por los Parlamentos autonómicos.

b) Precisión del contenido de la competencia senatorial del artículo 155 de la Constitución: el Gobierno central, previo requerimiento al Presidente de una Comunidad Autónoma, $y$, en el caso de no ser atendido, con la aprobación de la mayoría del Senado, podrá adoptar las medidas necesarias para obligar a dicha Comunidad Autónoma al cumplimiento de sus obligaciones constitucionales y legales.

c) El Senado debe ser foro permanente de encuentro entre el poder central y los autonómicos a fin de facilitar la participación de éstos en la formación de la voluntad estatal.

d) Por la vía de los usos parlamentarios, debería procederse a la participación de los miembros de los Gobiernos autonómicos y de representantes de otras instituciones de dicho 
nivel territorial en diversas comisiones de la Cámara, sin voto naturalmente.

II. El Grupo Popular hacía hincapié en los siguientes extremos:

a) La deseable comparecencia de los Presidentes de las Comunidades Autónomas en el Pleno y en las Comisiones del Senado.

b) El incremento del número de miembros de la Comisión de las Autonomías, con nuevas competencias.

c) La creación de Comisiones territoriales.

d) El refuerzo de los GruposTerritoriales en el seno de los Grupos Parlamentarios.

III. El Grupo del Centro Democrático y Social proponía unir las elecciones al Senado con las autonómicas y municipales, dar mayor relevancia al Senado en la deliberación de las leyes territoriales, celebrar un debate anual en el Senado sobre el estado de las Autonomías y reservar a esta Cámara, por vía de un acuerdo político, las Comisiones de Investigación.

IV. El Grupo de Convergencia y Unión pretendía que los Grupos Parlamentarios del Senado fueran territoriales y que debería poderse utilizar en dicha Cámara las lenguas oficiales de las distintas Comunidades Autónomas. Además, el Pleno debería debatir las mociones presentadas por los Gobiernos y Parlamentos autonómicos.

V. El Grupo Nacionalista Vasco presentó unos criterios generales, pero no una propuesta concreta de reforma.

VI. El Grupo Mixto, integrado por senadores de Izquierda Unida e Iniciativa por Cataluña, abogó decididamente por la reforma constitucional. Pero, en tanto ésta pudiera tener lugar, la Comisión de las Autonomías debería emitir dictamen preceptivo sobre la incidencia que en el terreno autonómico tuvieran todas las iniciativas legislativas. Igualmente, en el Senado deberían poder utlizarse todas las lenguas reconocidas en los Estatutos de Autonomia. 
Tras estas propuestas, la Ponencia nombrada en el seno de la Comisión de Reglamento adoptó un Acuerdo, el día 25 de abril de 1990, en el que, si bien intentaba no separarse ostensiblemente de ninguna de ellas, se inclinaba, como no podía ser menos, hacia los términos expresados por el Grupo Socialista, que tenía por aquel entonces la mayoría de la Cámara.

\section{CREACIÓN DE LA COMISIÓN GENERAL DE LAS COMUNIDADES AUTÓNOMAS}

Dos problemas suscitaron la mayor controversia: el uso de todas las lenguas oficiales de las Comunidades Autónomas y la forma de votación en la Comisión de las Autonomías, que habría de tener un nuevo diseño.

Dejando a un lado el problema lingüístico, el de la forma de voto enfrentó a los grupos socialista y popular. El primero exigía voto ponderado, ya que la composición de la Comisión iba a sufrir modificaciones, a lo que se oponía el segundo. La discusión se centraba en la constitucionalidad o no del voto ponderado, por su posible fricción con el artículo 79.3 de nuestro texto fundamental: «El voto de senadores y diputados es personal e indelegable». La doctrina se halla muy dividida sobre la materia, que no es sólo teórica, sino que, por disposición del Reglamento del Congreso, la Junta de Portavoces toma las decisiones con dicho tipo de voto, y la del Senado (sin disposición reglamentaria) también lo hace, digamos que por uso parlamentario. A mi juicio, el voto ponderado, por no ser propiamente personal y ser en cierto modo delegado, es inconstitucional. Pero, como digo, hay opiniones diferentes.

A partir de estas posiciones, la Cámara elaboró una propuesta conjunta - pues ése era el deseo de todos y el mandato formulado sobre dicho extremo - que no llegó a debatirse en el Pleno por disolución de la Cámara y convocatoria de elecciones.

Dicha propuesta conjunta se centraba sólo en la reforma del Reglamento de la Cámara y asumía como objeto prioritario la promoción de la presencia en ella de las instituciones autonómicas, para lo cual habrían de crearse en el Senado los órganos necesarios a fin de promover el estudio, debate y dictamen de los asuntos de interés autonómico que hubieran de conocer las Cortes. A ello contribuiria igualmente la participación de las instituciones autonómicas en los trabajos del Senado. Finalmente, se estudiaría el uso de las lenguas reconocidas en los Estatutos de Autonomía. 
Terminada la legislatura, las nuevas Cámaras presentaron un perfil distinto. El Partido Socialista quedó en mayoría relativa algo menguada en el Congreso, lo que le hacía dependiente de los grupos parlamentarios nacionalistas; $y$, si bien en el Senado mantenía la hegemonía, gracias precisamente a los senadores de nombramiento autonómico, no podía ni debía imponer su criterio en esta Cámara porque ponía en peligro los mencionados apoyos en la otra, que es la decisiva para gobernar.

Por eso, en seguida se matizó la propuesta proveniente de la anterior legislatura y, finalmente, se formuló una nueva, publicada en el Boletín Oficial de las Cortes el 22-X-1993. No se hicieron propuestas alternativas y el debate posterior introdujo solamente leves modificaciones. Sus rasgos más característicos eran los siguientes:

1) Se creó una Comisión General de las Comunidades Autónomas, con carácter de permanente y no legislativa.

2) Su composición es del doble de miembros de las demás comisiones. Para ello, cada Grupo Parlamentario designará al doble de senadores que para las otras.

Se pretendía evitar el número desmesurado de miembros de la propuesta anterior y el problema del voto ponderado. Según la composición aprobada, la Comisión queda integrada por 62 senadores. Algunos senadores, designados por los Parlamentos autonómicos, no pueden ser miembros de esta Comisión, por exceder del cupo de su respectivo grupo. Dichos senadores son advertidos de la celebración de las sesiones de la Comisión y pueden asistir a ellas e inscribirse como oradores, pero no votar.

3) Las funciones de la Comisión son de estudio, informe y propuesta. Puede decirse que todo asunto de interés autonómico que llegue a las Cortes habría de ser estudiado por la citada Comisión, o, al menos, ésta debería de ser informada del problema por el Gobierno, con lo que su actividad autonómica crecería exponencialmente. Pero, como hemos adelantado, no será un trabajo legislativo, sino de informe $y$ estudio.

4) Pueden intervenir en las sesiones tanto el Gobierno central como los Consejos de Gobierno autonómicos.

5) Celebra una vez al año una sesión-balance sobre el estado de las autonomías, en la que se pueden presentar mociones 
y utilizar las lenguas reconocidas en los Estatutos de Autonomía (como también en la sesión de apertura de cada legislatura).

6) La Comisión tiene competencia, al igual que el Gobierno o 25 senadores, para proponer al Senado que aprecie la necesidad de una ley de armonización y posteriormente informar dicha propuesta (se supone que es necesario este informe si la propuesta viene del Gobierno o de 25 senadores, no si es de la propia Comisión).

7) $Y$ se prescinde de la idea de formar los Grupos Parlamentarios como GruposTerritoriales, como es lógico, dada la prohibición de mandato imperativo. Lo contrario sería tanto como inutilizar los Grupos Parlamentarios, por cuanto éstos no podrían tener una política unitaria y tendrían muchas dificultades en designar sus miembros en las distintas comisiones, pues, según fuera el senador o senadores designados, podría cambiar la correlación de fuerzas de los partidos políticos, que, al fin y al cabo, están en la base de todo.

Se constituyó, pues, la Comisión General de las Comunidades Autónomas e incluso celebró una sesión, bastante positiva por su desarrollo y debate (a pesar de la inasistencia del lehendakari Sr. Ardanza), pero evidenció su cortedad de miras. Las necesidades del Senado eran de más largo alcance. Como la reforma llevada a cabo no afectaba ni a la composición del Senado ni a sus funciones, en seguida se manifestó como insuficiente. La utilización de las distintas lenguas españolas en algunas sesiones es importante, pero apenas pasa del simbolismo. Y la creación de esa Comisión General no deja de ser una burbuja: aunque su composición es de perfil más autonómico, no estamos ante una comisión legislativa, sino de estudio e informe. $Y$ para ese viaje...

Ya es sintomático que una de las conclusiones (no expresas) de la primera y única sesión de la mencionada Comisión General (lo que ya es sintomático) sobre el estado de las autonomias fuera la de que había que continuar por el camino de la reforma, instituyéndose una Comisión de Estudio de la Reforma, que trabajó bien durante unos meses. Por ella desfilaron los Presidentes autonómicos y un buen número de expertos que dieron su versión de ésta.

Durante la legislatura (1993-1996) fue ganando terreno la opinión, entre las fuerzas políticas, de que, sin reforma constitucional, el Senado no puede ser propiamente una Cámara territorial. Ya algunos 
grupos (el Nacionalista Vasco, el catalán de Convergencia y Unión y el Mixto) lo habían dicho así. Y en la campaña electoral subsiguiente los Partidos Socialista y Popular terminaron admitiendo la posibilidad de una reforma constitucional al respecto. Después se admitió algo más: la reforma reglamentaria podía ser un primer paso para, según se fuera observando en la práctica, proceder ulteriormente a la reforma de los preceptos constitucionales pertinentes. Sin embargo, el resultado electoral, con triunfo del Partido Popular (incrementado en las elecciones del año 2000), paralizó esta iniciativa y en la actualidad se vuelve a pensar en una reforma exclusivamente reglamentaria.

\section{REFORMA CONSTITUCIONAL DEL SENADO}

\subsection{Búsqueda de un modelo de Senado como Cámara autonómica}

Lo primero que no se tiene claro es si se quiere un Senado y qué Senado se quiere, si bien casi todos apuntan a hacer de él una Cámara autonómica. Pero es un error que, como dijo algún líder político, esa reforma constitucional se circunscribiera sólo al artículo 69, que regula la composición de la Cámara. Como ya hemos comentado, ni puede haber una Cámara con competencias autonómicas y la composición actual, ni tampoco una Cámara de composición territorial pero sin competencias en este terreno. Una Cámara verdaderamente territorial sólo lo puede ser si lo es en su composición, en sus funciones y en su funcionamiento.

Echando una mirada a la Constitución, una reforma de tal calibre afectaría a una veintena de preceptos constitucionales. Acaso otros, igualmente susceptibles de reforma, deban permanecer en su redacción actual por no ser tan vitales y porque las reformas constitucionales, como operaciones políticas trascendentes, deben hacerse con prudencia y afectar al menor número posible de artículos. Aun así, comprendo que hablar de unos veinte artículos parezca demasiado y muchos se retraigan. Pero, entonces, sepamos que no vamos a tener un Senado verdaderamente autonómico. Los parches pueden servir para ir tirando, pero no logran ocultar el problema.

En fin, si se quiere un Senado territorial, todavia queda la cuestión previa del modelo de Senado autonómico que se desea instaurar. Entre el modelo estadounidense y el alemán, era corriente dominan- 
te durante los años noventa la preferencia por el federalismo o autonomismo cooperativo alemán y, por consiguiente, también por el Bundesrat o Consejo Federal mejor que por el Senado norteamericano.

El Senado americano responde a su momento, hace más de dos siglos, y a la forma en que se construyó la Unión, por asociación de Estados preexistentes muy celosos de su soberanía y muy recelosos de la gran Federación que estaban edificando. De ahí la igualdad de representación estatal y las competencias decisivas del Senado en politica nacional e internacional. Hasta tal punto es así que la Cámara de Representantes, que es la de la Unión, la que representa a la población de la Unión como un todo, es más localista que el Senado, que es la Cámara de representación de los Estados.

Por su parte, el Bundesrat alemán es una institución semiparlamentaria, cuyos miembros son designados por los Gobiernos de los Länder, y están sometidos a mandato imperativo. Es una institución de cooperación de la Federación con los Länder y de éstos entre sí, aparte de que en determinadas ocasiones puede desempeñar otras funciones.

A mi juicio, en España hay que buscar un órgano de cooperación, como el Bundesrat, pero que sea plenamente una Cámara parlamentaria: a) cuyos miembros estén nombrados por los Parlamentos autonómicos en vez de por los Gobiernos; b) con inmunidad, inviolabilidad y no sometidos a mandato imperativo; c) que sea Cámara especial por su representación (de las Comunidades Autónomas) y por sus competencias (casi exclusivamente autonómicas); d) e indisoluble. Lo cual necesita explicación.

\subsection{Composición, estatuto de sus miembros e indisolubilidad}

El Bundesrat alemán responde al principio de mandato imperativo sin que por ello se agriete el edificio constitucional sostenido en todo lo demás por el principio inverso: mandato representativo. Cabría hacer otro tanto en España. Pero, si ya le cuesta trabajo a la opinión pública aceptar la disciplina de voto de los parlamentarios respecto de sus grupos y de sus partidos políticos, mucho más difícil le sería no ver en el mandato imperativo de los Gobiernos o Parlamentos autonómicos una disolución del Estado en las Comunidades Autónomas. De otro lado, el Bundesrat es una semi-cámara parlamentaria. Muchos autores califican de unicameral el Parlamento alemán, no viendo en el Consejo Federal sino un órgano con ciertas facultades de veto legis- 
lativo, reglamentario y de cooperación, función que no requiere necesariamente una Cámara parlamentaria. En conclusión, los senadores no deberían estar ligados por mandato imperativo alguno.

Por su parte, el artículo 69 es central en una reforma del Senado, a partir del cual se irradian las conexiones con otros problemas.

Son posibles diferentes soluciones, incluido un Senado de notables (Herrero de Miñón), pero las propuestas más leídas son las que procuran acentuar en mayor o menor grado el carácter autonómico de la Cámara. Nuestra posición va en esa misma dirección.

El apartado primero del artículo mencionado podría quedar igual a pesar de su torpe redacción, aunque el lenguaje nunca es indiferente en Derecho. Pero el apartado segundo debería introducir el nombramiento de los senadores por los Parlamentos autonómicos: «Las Asambleas legislativas de las Comunidades Autónomas designarán de entre sus miembros y en proporción a la importancia numérica de sus grupos parlamentarios, los senadores que correspondan a su respectiva Comunidad". Fórmula que se separa en un par de rasgos del Consejo Federal alemán.

De otro lado, dada la armonización actual de la regulación de las elecciones autonómicas, el apartado tercero del comentado artículo constitucional depararía un Senado designado por trece Comunidades simultáneamente en el mes de junio/julio de cada cuatro años. Los senadores de las otras cuatro Comunidades (Andalucía Cataluña, Galicia y País Vasco se incorporarian conforme al ritmo electoral de cada una. Por tanto, el apartado podría quedar como sigue: "Las Asambleas Legislativas procederán a la designación de senadores una vez constituidas después de las correspondientes elecciones».

Naturalmente, es opcional la ratio población-senador. Puede ser uno por cada millón de habitantes o fracción superior a quinientos mil, algo más o algo menos. A lo que se añadiría, en beneficio de la representación de las Comunidades menores, un senador por cada una independientemente de su población. Ello arrojaría un total de unos 84 u 86 senadores; cantidad que puede variar, aunque no mucho, según los movimientos de población. Puede buscarse ly a mi juicio, se debe) un Senado de unos 100-105 miembros, como el Senado de Estados Unidos, incrementando en una unidad los de cada Comunidad Autónoma. Ello se conseguiría confiriendo el carácter de senadores natos a los Presidentes de las Comunidades Autónomas en ejercicio, aspecto éste que aumentaría la simbología representativa (y algo 
más que la simbología) de la Cámara respecto de la composición territorial del Estado. En fin, las Ciudades Autónomas de Ceuta y Melilla designarían un senador cada una. Todo lo cual debería tener reflejo en sendos apartados del referido artículo 69.

La composición resultante parece suficiente, para las competencias que debe desempeñar, significa un ahorro tangible en su sostenimiento, que merecerá la aprobación de la opinión pública, y ofrece unas diferencias moderadas entre unas Comunidades Autónomas y otras, en función de su población, sin que la más presente (seguramente Andalucía y Cataluña) llegue a triplicar a las menos pobladas (Rioja, Murcia, Cantabria...).

En cuanto al estatuto jurídico de los senadores, no necesita ningún ajuste constitucional. El modelo alemán puede sugerirnos la idea de negar inmunidad e inviolabilidad a los senadores. Pero es que, como ya hemos dicho, el Consejo Federal no es una Cámara parlamentaria propiamente dicha. Por eso, junto a la independencia del voto, debe seguírseles reconociendo a los senadores las mencionadas prerrogativas, aunque - lo mismo en este caso que en el de los diputados - su interpretación deba ser restringida. Pero éste es otro problema.

Por último, como el Senado así diseñado no es elegido directamente por el pueblo español, sino indirectamente a través de los Parlamentos autonómicos, carece de sentido su disolución por parte del Ejecutivo porque no hay elecciones nuevas que convocar. Asi, junto a su indisolubilidad, tendríamos su renovación tras cada constitución de los Parlamentos autonómicos. Por eso, debería corregirse el artículo 115 de la Constitución para hacer del Congreso la única Cámara disoluble por el Gobierno.

\subsection{Función legislativa del Senado}

Creo que sería conveniente una modificación del artículo 81.2, que regula parcialmente el procedimiento legislativo orgánico y en el que se ventila de modo más acusado el perfil de la reforma pretendida. Si finalmente se busca un Senado que sea verdadera Cámara parlamentaria, pero igualmente su singularización autonómica respecto del Congreso de los Diputados, hemos de diseccionar bien las competencias de las Cortes y distribuirlas entre las dos Cámaras de la forma más funcional posible. 
Por lo que a la legislación orgánica se refiere, parece plausible atribuir al Senado mayor peso específico en materia autonómica y al Congreso en las demás. De ahí que el precepto aludido deba conjugarse con los otros que regulan el procedimiento legislativo (arts. 87, 89 y 90) en un todo armónico, que podría quedar como sigue:

1. La aprobación, modificación y derogación de los Estatutos de Autonomía exigirá mayoría absoluta del Senado en una votación sobre el conjunto del proyecto.

2. Las Asambleas Legislativas de las Comunidades autónomas podrán solicitar del Senado la adopción de una proposición de ley sobre una materia que afecte a la organización territorial del Estado o remitírsela directamente, delegando ante él un máximo de tres de sus miembros encargados de su defensa.

3. Debe cambiar, de manera acorde, la tramitación de los proyectos y proposiciones de ley, terminando con la actual supeditación del Senado respecto del Congreso. La distribución funcional debe hacerse en atención a la materia, de manera que la relativa al Estado autonómico encuentre en el Senado la Cámara especial y prioritariamente competente. Viceversa: en el resto, debe serlo el Congreso de los Diputados. Por tanto, bastaría con un nuevo apartado del artículo 88, que dijera: "Los proyectos y proposiciones de ley relativos a la organización autonómica y a su financiación serán tramitados primeramente en el Senado, a cuyos efectos le serán remitidos por el Gobierno y por el Congreso de los Diputados». Con este nuevo texto y con la reforma del artículo 87.2, carece de objeto el 89.2, que debería, por ende, desaparecer.

4. Por iguales motivos, el artículo 90 se ve afectado. Al tramitarse algunos textos legislativos primeramente en el Senado, la actual regulación de los trámites sucesivos debería ser completada con la de estos proyectos y proposiciones. De otro lado, el incremento de significación autonómica del Senado, permite descargarlo del grueso de la tramitación legislativa de los demás textos, circunscribiéndose a la interposición de vetos, pero no la presentación, debate y votación de enmiendas. Con ello y con la reducción de plazos, se agilizaría sobremanera el procedimiento legislativo. Los vetos senatoriales deberían requerir la mayoría absoluta y ser superables por el Congreso en términos parecidos a los actualmente establecidos en el artículo 90.2. Esta reforma no 
requiere, sin embargo, una redacción de nuevo cuño del artículo 90 , sino leves retoques en sus apartados segundo y tercero y la adición de un cuarto nuevo: "Los proyectos que deban ser tramitados primeramente en el Senado seguirán el camino inverso, con iguales formalidades y plazos".

5. Igual sucede con las leyes de armonización. Es oportuno reformar el artículo 150.3 en el sentido de conferir al Senado en exclusiva la apreciación de la necesidad de armonizar las legislaciones de las Comunidades Autónomas: "El Estado podrá dictar... Corresponde al Senado, por mayoría absoluta, la apreciación de esta necesidad».

\subsection{Otras funciones}

Iguales o similares retoques podrían hacerse en las funciones presupuestaria y de control, así como en la participación del Senado en la reforma constitucional. Su hilo conductor debería ser siempre el atribuirle mayor protagonismo en los asuntos de interés autonómico y restárselo -o incluso suprimirlo - en el resto. Pero valga lo expuesto aquí para hacernos una idea del alcance de una reforma constitucional a fin de hacer del Senado una Cámara verdaderamente autonómic̀a. Reforma que no puede circunscribirse, como se ha pretendido, a la del artículo 69 de nuestro texto fundamental.

Éste ha sido un ejercicio intelectual. Es más fácil, claro está, decirlo que hacerlo. Pero, al menos, hay que decirlo. Creo que en torno a la reforma constitucional para este motivo se va disipando el consenso alcanzado en 1996. Mucho tiene que ver con ello, el cáncer del Norte, que determina, por prudencia política, no acometer tareas de tal envergadura. Pero alguna vez habrá que hacer frente a los recelos. $Y$, lo mismo que ocurrió con la (frustrante) reforma del Reglamento, que tardó cinco años en cuajar, esta otra también habría de ser lenta. Sin embargo, alguna vez hay que empezar. El mejor funcionamiento del Estado autonómico está en juego. 


\section{BALANCE}

Las conclusiones que podemos extraer de este comentario como balance de los veinticinco años de Senado son:

1. El Senado no ha sido, ni habria podido ser, una Cámara de representación territorial como dice el artículo 69 de la Constitución. El resto de dicho precepto y todo el texto fundamental lo impiden.

2. Como Cámara de segunda lectura ha sido más bien secundaria. No obstante, muchos proyectos de ley que le han llegado del Congreso en condiciones técnico-jurídicas deficientes han sido muy mejorados por el Senado.

3. Se ha introducido una práctica torticera en la última legislatura, conforme a la cual la mayoría introduce en el trámite senatorial importantes enmiendas en un proyecto de ley, aceptadas luego en bloque por el Congreso, con lo que se hurta a la Cámara legislativa principal el oportuno debate con la Oposición. Tengo dudas sobre la corrección constitucional de dicha práctica.

4. Se ha sentido desde el principio la necesidad de reformar el Senado. Pero, por recelo a hacerlo mediante una modificación constitucional, se ha procurado introducir en el Reglamento de la Cámara algunos procedimientos que mejoren su carácter autonómico.

5. Esta reforma "reglamentaria" del Senado se ha evidenciado insuficiente, incluida la creación de la Comisión General de las Comunidades Autónomas, que apenas ha funcionado $y$ en la que sólo se ha celebrado un debate sobre el estado de las Autonomías.

6. La reforma constitucional del Senado no puede cifrarse en la del artículo 69 únicamente. Para que el Senado sea verdaderamente una Cámara autonómica, debe serlo por su composición, por sus funciones y por su funcionamiento, lo que obliga a retocar no menos de una docena de artículos constitucionales, operación de tal calado que las fuerzas políticas se han retraído, comenzando por la que ha ostentado la mayoría en las dos últimas legislaturas. 